\title{
Wide-neck bifurcation aneurysms of the middle cerebral artery and basilar apex treated by endovascular techniques: a multicentre, core lab adjudicated study evaluating safety and durability of occlusion (BRANCH)
}

\author{
Reade A De Leacy, ${ }^{1}$ Kyle M Fargen, ${ }^{2}$ Justin R Mascitelli, ${ }^{1}$ Johanna Fifi, ${ }^{1}$ \\ Lena Turkheimer, ${ }^{1}$ Xiangnan Zhang, ${ }^{1}$ Aman B Patel, ${ }^{3}$ Matthew J Koch, ${ }^{3}$ \\ Aditya S Pandey, ${ }^{4}$ D Andrew Wilkinson, ${ }^{4}$ Julius Griauzde, ${ }^{4}$ Robert F James, ${ }^{5}$ \\ Enzo M Fortuny, ${ }^{5}$ Aurora Cruz, ${ }^{5}$ Alan Boulos, ${ }^{6}$ Emad Nourollah-Zadeh, ${ }^{6}$ \\ Alexandra Paul, ${ }^{6}$ Eric Sauvageau, ${ }^{7}$ Ricardo Hanel, ${ }^{7}$ Pedro Aguilar-Salinas, ${ }^{7}$ \\ Roberta L Novakovic, ${ }^{8}$ Babu G Welch, ${ }^{8}$ Ranyah Almardawi, ${ }^{9}$ Gaurav Jindal, ${ }^{9}$ \\ Harish Shownkeen, ${ }^{10}$ Elad I Levy, ${ }^{11}$ Adnan H Siddiqui,, ${ }^{11} \mathrm{~J} \mathrm{Mocco}^{1}$
}

For numbered affiliations see end of article.

\section{Correspondence to} Dr Reade A De Leacy, Department of Neurosurgery, Mount Sinai Hospital, New York City, NY 10029, USA; reade. deleacy@mountsinai.org

Received 30 January 2018 Revised 17 April 2018 Accepted 18 April 2018 Published Online First 17 May 2018
Check for updates

To cite: De Leacy RA, Fargen KM, Mascitelli JR, et al. J Neurolntervent Surg 2019;11:31-36.

\section{ABSTRACT}

Background and purpose BRANCH (wide-neck bifurcation aneurysms of the middle cerebral artery and basilar apex treated by endovascular techniques) is a multicentre, retrospective study comparing core lab evaluation of angiographic outcomes with self-reported outcomes.

Materials and methods Consecutive patients were enrolled from 10 US centres, aged between 18 and 85 with unruptured wide-neck middle cerebral artery (MCA) or basilar apex aneurysms treated endovascularly. Patient demographics, aneurysm morphology, procedural information, mortality and morbidity data and core lab and self-reported modified Raymond Roy (RR) outcomes were obtained.

Results 115 patients met inclusion criteria. Interventionrelated mortality and significant morbidity rates were $1.7 \%(2 / 115)$ and $5.8 \%$ (6/103) respectively. Core lab adjudicated RR 1 and 2 occlusion rates at follow-up were $30.6 \%$ and $32.4 \%$ respectively. The retreatment rate within the follow-up window was $10 / 115(8.7 \%)$ and in stent stenosis at follow-up was 5/63 (7.9\%). Self-reporting shows a statistically significant direction to angiographic RR one outcomes at follow-up compared with core lab evaluation, with OR 1.75 (95\% Cl 1.08 to 2.83).

Conclusion Endovascular treatment of wide-neck MCA and basilar apex aneurysms resulted in a core lab adjudicated RR1 occlusion rate of $30.6 \%$. Self-reported results at follow-up favour better angiographic outcomes, with OR 1.75 ( $95 \% \mathrm{Cl} 1.08$ to 2.83). These data demonstrate the need for novel endovascular devices specifically designed to treat complex intracranial aneurysms, as well as the importance of core lab adjudication in assessing outcomes in such a trial.

\section{INTRODUCTION}

The endovascular treatment of both ruptured and unruptured intracranial aneurysms has become first-line management since the publication of the International Subarachnoid Aneurysm Trial (ISAT) results in 2002. ${ }^{1}$ However, until recently, widenecked bifurcation aneurysms have classically been considered poor candidates for endovascular therapy. Standard coiling techniques are limited in their effectiveness at occluding these challenging types of aneurysms, with high recanalisation rates and the risk of parent vessel coil protrusion with potential thromboembolic consequences.

However, advances in endovascular techniques such as balloon-assisted coiling (BAC) and stent-assisted coiling (SAC) have allowed such aneurysms to be considered candidates for endovascular treatment. ${ }^{2-6}$ The inherent technical challenges associated with endovascular treatment of this subgroup of aneurysms has led to the ongoing development of wide-neck aneurysm specific bridging devices, intrasaccular flow disruption devices and the off-label use of flow diversion. ${ }^{7}$ However, at the time of writing this paper, these devices are not widely available for use in the United States.

Currently published data specifically evaluating the endovascular treatment of wide-necked bifurcating type aneurysms are derived from retrospective series using self-reported and not core lab adjudicated angiographic outcomes. The current literature demonstrates that retrospective non-independently evaluated studies consistently overestimate the treatment benefit and underestimate complication rates. ${ }^{8}$ We present a retrospective, multicentre, core lab adjudicated series of wideneck bifurcating type aneurysms of the basilar apex and middle cerebral artery (MCA) bifurcation using on-label, FDA-approved devices evaluating durability of occlusion and safety, and investigating any discrepancy between self-reported and core lab outcomes. 


\section{PATIENTS AND METHODS}

Ten US centres provided retrospective, de-identified data on up to a maximum of 15 consecutive patients per site, who underwent endovascular treatment of unruptured wide-neck bifurcation type MCA or basilar apex aneurysms using FDA-approved devices up to January 2017 . A total of $88.8 \%$ of enrolled patients underwent treatment between January 2012 and January 2017. The first aneurysm treatment took place in May 2005. Aneurysms were considered wide necked if the longest neck dimension was between 4 and $8 \mathrm{~mm}$ inclusive or if the dome to neck ratio was $\leq 2.0$.

All centres obtained institutional review board approval prior to data submission to the primary centre. Procedural technique and perioperative management including anti-aggregate therapy were non-standardized and based on standard of care at the individual treating centre. Consecutive patients with clinical and angiographic follow-up available 6-18 months after the index procedure were included.

\section{Patient demographics, aneurysm and procedural details and self-reported outcomes}

Patient demographics including patient age, sex, ethnicity/race and pertinent past medical history were collected. Aneurysm and angiographic details including aneurysm size, shape, neck dimension, dome to neck ratio, location, treatment method (unassisted, BAC or SAC), type of stent used and self-reported initial and follow-up angiographic occlusion (assessed using the modified Raymond Roy scale) were provided by each institution. ${ }^{9}$ Intra-procedural and post-procedural complication rates and types were reported for each patient, in addition to patient baseline and follow-up modified Rankin scale (mRS) data.

\section{Core lab evaluation}

The core lab consisted of an experienced neurointerventionalist (KF) from a non-enrolling site blinded both to patient and site identifiers. De-identified digital subtraction angiographic images were uploaded to a secure database by each site for evaluation by the imaging core lab. Pre and immediate post treatment standard anterioposterior and lateral whole head and magnified biplane working projection images were provided for evaluation. For follow-up imaging, either digital subtraction angiographic images or high-quality magnetic resonance angiography (MRA) images were uploaded as determined by the standard of care of the submitting sites. MRA follow-up was permitted due to its reported accuracy in the detection of recanalisation in coiled aneurysms. ${ }^{10}$ The core lab evaluated aneurysm occlusion using the modified Raymond Roy scale and the presence of in stent stenosis at follow-up.

\section{Statistical evaluation}

Descriptive statistical analysis results were summarised and presented using means with SD and frequencies with percentages for continuous and categorical variables respectively; t test and Fisher's exact test were conducted for comparison. A P-value $<0.05$ was considered statistically significant, all tests were two sided if not stated otherwise. Shift analysis was performed by using a logistic proportional OR model. The categorical and ordinal analysis results for group comparison were evaluated and interpreted with odds ratios and corresponding 95\% confidence intervals. All statistical analyses were performed and testified byR software (Version 3.4.1) and SAS software (Statistical Analysis Software, Version 9.4)

\begin{tabular}{|c|c|}
\hline Characteristics & Pool \\
\hline Age $($ mean $\pm S D)$ & $61.0 \pm 11.6$ \\
\hline Male sex (N/total (\%)) & $30 / 115(26.1)$ \\
\hline \multicolumn{2}{|l|}{ Race (N/total (\%)) } \\
\hline American Indian/Alaskan Native & $0 / 115(0)$ \\
\hline Asian & $0 / 115(0)$ \\
\hline Black/African American & $2 / 115(1.7)$ \\
\hline Native Hawaiian/Pacific Islander & $0 / 115(0)$ \\
\hline White & $82 / 115(71.3)$ \\
\hline Other & $0 / 115(0)$ \\
\hline \multicolumn{2}{|l|}{ Medical history (N/total (\%)) } \\
\hline Arrhythmia & $5 / 115(4.3)$ \\
\hline Brain tumour & $1 / 115(0.9)$ \\
\hline Carotid atery atheroma & $3 / 115(2.6)$ \\
\hline Coarctation of aorta & $0 / 115(0)$ \\
\hline Congestive heart failure & $5 / 115(4.3)$ \\
\hline Coronary artery disease & 13/115 (11.3) \\
\hline Diabetes type 1 & $1 / 115(0.9)$ \\
\hline Diabetes type 2 & $14 / 115(12.2)$ \\
\hline Endocarditis & $0 / 115(0)$ \\
\hline Gastrointestinal bleeding & $0 / 115(0)$ \\
\hline Head injury & $5 / 115(4.3)$ \\
\hline Hyperlipidaemia & $43 / 115(37.4)$ \\
\hline Hypertension & $74 / 115(64.3)$ \\
\hline Migraines & $20 / 115(17.4)$ \\
\hline Myocardial infarction & $4 / 115(3.5)$ \\
\hline Obesity & $6 / 115(5.2)$ \\
\hline Peripheral artery disease & 9/115 (7.8) \\
\hline Platelet disorder & $3 / 115(2.6)$ \\
\hline Polycystic kidney & $2 / 115(1.7)$ \\
\hline Renal insufficiency & $7 / 115(6.1)$ \\
\hline Seizures & $6 / 115(5.2)$ \\
\hline Subarachnoid haemorrhage & $5 / 115(4.3)$ \\
\hline Other & $80 / 115(69.6)$ \\
\hline \multicolumn{2}{|l|}{ Smoking status (N/total (\%)) } \\
\hline Never & $44 / 115(38.3)$ \\
\hline Prior & $38 / 115(33)$ \\
\hline Current & 29/115 (25.2) \\
\hline
\end{tabular}

\section{RESULTS}

\section{Participants and procedural details}

A total of 115 patients from 10 centres fulfilled criteria for enrollment. Patient demographic and clinical data are presented in table 1 and aneurysm morphological data in table 2. Patient mean age was 61.0 years (SD \pm 11.63$)$. Twenty-six percent of patients were men (30/115). Forty-six aneurysms were located at the MCA bifurcation $(46 / 115,40 \%)$ and 69 at the basilar apex (60\%). Thirty-seven aneurysms $(32.2 \%)$ were treated with standalone coiling, $70(60.9 \%)$ with SAC and 8 (7.0\%) with BAC. Five cases required conversion from intended balloon assistance to stent assistance intra-procedurally and these were included in the stent-assisted category for evaluation. For the stent-assisted 
Table 2 Aneurysm characteristics by total pool and aneurysm location

\begin{tabular}{|c|c|c|c|c|}
\hline \multirow[b]{2}{*}{ Characteristics } & \multirow[b]{2}{*}{ Pool } & \multicolumn{2}{|c|}{ By aneurysm location } & \multirow[b]{2}{*}{$P$ value } \\
\hline & & $\begin{array}{l}\text { MCA } \\
\text { bifurcation }\end{array}$ & Basilar apex & \\
\hline \multicolumn{5}{|c|}{ Aneurysm shape (N/total (\%)) } \\
\hline Spherical & $55 / 115(47.8)$ & $22 / 46(47.8)$ & $33 / 69(47.8)$ & 1.0 \\
\hline Ellipsoid & $35 / 115(30.4)$ & $12 / 46(26.1)$ & $23 / 69(33.3)$ & 0.54 \\
\hline Bilobed & 15/115 (13.0) & $8 / 46(17.4)$ & $7 / 69(10.1)$ & 0.27 \\
\hline Multilobed & $10 / 115(8.7)$ & $4 / 46(8.7)$ & $6 / 69(8.7)$ & 1.0 \\
\hline \multicolumn{5}{|l|}{ Aneurysm side (N/total (\%)) } \\
\hline Right & $25 / 115(21.7)$ & $25 / 46(54.3)$ & $\mathrm{n} / \mathrm{a}$ & - \\
\hline Left & 21/115 (18.3) & $21 / 46(45.7)$ & $\mathrm{n} / \mathrm{a}$ & - \\
\hline Midline & $69 / 115(40)$ & $\mathrm{n} / \mathrm{a}$ & $69 / 69(100)$ & - \\
\hline $\begin{array}{l}\text { Aneurysm neck size } \\
(\text { mean } \pm S D)\end{array}$ & $4.57 \pm 1.59$ & $4.16 \pm 1.26$ & $4.85 \pm 1.73$ & 0.1 \\
\hline $\begin{array}{l}\text { Dome to neck ratio } \\
(\text { mean } \pm S D)\end{array}$ & $1.48 \pm 0.35$ & $1.56 \pm 0.39$ & $1.42 \pm 0.31$ & 0.04 \\
\hline $\begin{array}{l}\text { Maximum diameter }(\mathrm{mm}) \\
(\mathrm{mean} \pm \mathrm{SD})\end{array}$ & $7.65 \pm 2.95$ & $7.64 \pm 2.83$ & $7.66 \pm 3.05$ & 0.9 \\
\hline $\begin{array}{l}\text { Retreatment rate (N/total } \\
(\%))\end{array}$ & $10 / 115(8.7)$ & $2 / 46(4.3)$ & $8 / 69$ (11.6) & 0.31 \\
\hline $\begin{array}{l}\text { In-stent stenosis rate at } \\
\text { follow-up (N/total (\%)) }\end{array}$ & $5 / 67(7.5)$ & $3 / 23^{13}$ & $2 / 44(4.5)$ & 0.33 \\
\hline $\begin{array}{l}\text { Aneurysm rupture during } \\
\text { follow-up period (N/total } \\
(\%) \text { ) }\end{array}$ & $1 / 115(0.9)$ & $1 / 46(2.2)$ & $0 / 69(0.0)$ & 0.4 \\
\hline
\end{tabular}

cohort, 24/70 (34.3\%) patients were treated with the Neuroform stent (Stryker, Kalamazoo, Michigan, USA), 20/70 patients (28.6\%) with the Enterprise vascular Reconstruction device
(Codman Neurovascular, Ratham, Massachusetts, USA) and 26/70 patients (37.1\%) with the Low Profile Intraluminal Support LVIS/LVIS Jr (Microvention-Terumo, Tustin, California, USA).

The mean maximum aneurysm diameter was $7.65 \mathrm{~mm}$ (SD \pm 2.95$)$ and mean aneurysm neck dimension was $4.57 \mathrm{~mm}$ $(\mathrm{SD} \pm 1.59)$. Average dome to neck ratio was 1.48 ( $\mathrm{SD} \pm 0.35$ ). Average follow-up duration was 48.75 weeks $(S D \pm 35.62$, min 5, max 269 weeks) (figure 1).

\section{Self-reported versus core lab outcomes}

For the total pool, aneurysm occlusion assessment using the modified Raymond Roy classification demonstrated a statistically significant direction towards RR1 results with self-reporting outcomes compared with independent core lab evaluation immediately following treatment (OR 1.84, 95\% CI 1.15 to 2.95 ) and at follow-up (OR 1.75, 95\% CI 1.08 to 2.83) (table 3).

Aneurysm groups were then separated by anatomic location and evaluated. At both initial and follow-up review, occlusion rates trended towards RR1 results with self-reporting for basilar apex aneurysms without reaching statistical significance (initial OR 1.66, 95\% CI 0.9 to 3.04; follow-up OR 1.67, 95\% CI 0.9 to 3.04). For MCA bifurcation aneurysms, a statistically significant direction towards RR1 results with self-reported outcomes was seen at initial evaluation (OR 2.27, 95\% CI 1.06 to 4.86 ) and a non-statistically significant trend at follow-up (OR 1.84, 95\% CI 0.85 to 3.98$)$.

\section{Occlusion outcomes}

The core lab was unable to evaluate follow-up occlusion outcomes in two patients due to suboptimal imaging. Initial adequate aneurysm occlusion (defined as RR1 or 2), as assessed by the core

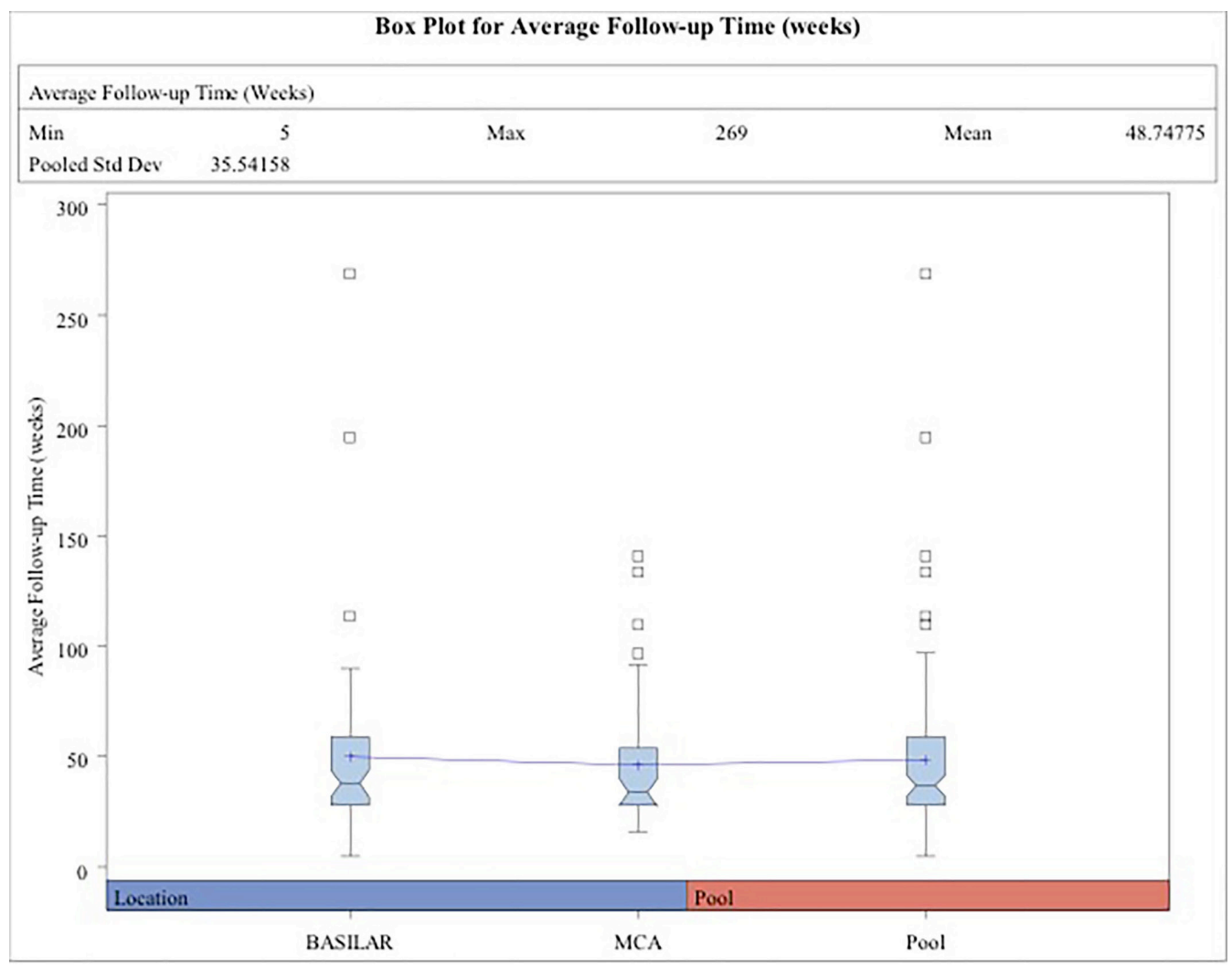

Figure 1 Box plot with average clinical and radiological follow-up time in weeks for basilar aneurysms, middle cerebral artery aneurysms and the combined aneurysm pool. Interconnecting point between groups on diagram demonstrates means. 
Hemorrhagic Stroke

Table 3 Occlusion outcomes. Initial and follow-up modified Raymond Roy scores for the pool. Comparison of self-reported and core lab review

\begin{tabular}{|c|c|c|c|c|c|c|}
\hline \multirow{2}{*}{$\begin{array}{l}\text { Modified Raymond Roy score, } \\
\text { N (\%) }\end{array}$} & \multicolumn{3}{|c|}{ Immediately post treatment } & \multicolumn{3}{|l|}{ Follow-up } \\
\hline & Self-reported & Core lab & Odds ratio $(95 \% \mathrm{Cl})$ & Self-reported & Core lab & Odds ratio $(95 \% \mathrm{Cl})$ \\
\hline Class 1: complete obliteration & $22(19.1)$ & $20(17.7)$ & \multirow{4}{*}{$\begin{array}{l}1.84 \\
\text { (1.14 to } 2.95)\end{array}$} & $45(40.2)$ & $34(30.6)$ & \multirow{4}{*}{$\begin{array}{l}1.75 \\
\text { (1.08 to } 2.83 \text { ) }\end{array}$} \\
\hline Class 2: residual neck & 39 (33.9) & $26(23)$ & & $34(30.4)$ & $36(32.4)$ & \\
\hline Class 3a: residual aneurysm with contrast within coil interstices & $37(32.2)$ & $27(23.9)$ & & $22(19.6)$ & $6(5.4)$ & \\
\hline Class 3b: residual aneurysm with contrast along aneurysm wall & $17(14.8)$ & $40(35.4)$ & & $11(9.8)$ & $35(31.5)$ & \\
\hline
\end{tabular}

lab, was demonstrated in 40.7\% (RR1, 17.7\%; RR2, 23\%). At follow-up, adequate aneurysm occlusion was seen in 63\% (RR1, $30.6 \%$; RR2, 32.4\%). Retreatment within the follow-up period was required for 10/115 aneurysms (8.7\%).

In stent stenosis of $<50 \%$ was seen in $5 / 67$ patients $(7.5 \%)$. The presence of in stent stenosis could not be evaluated in three patients who underwent SAC due to suboptimal imaging.

\section{Procedural morbidity and mortality data}

Baseline and follow-up mRS data were available for 105 (91.3\%) and $103(89.6 \%)$ patients respectively.

Ten of 103 patients (9.7\%) suffered deterioration in their baseline mRS at clinical follow-up, with six of these patients deteriorating to mRS 3-6 (5.8\%). Procedure-related mortality was $1.7 \%(2 / 115)$ and all cohort death or permanent disability at follow-up was seen in $6.8 \%$ of patients $(7 / 103)$. The two procedure-related mortalities arose from the SAC cohort $(2.8 \%)$. The first patient died on postoperative day eight following dissection of the parent basilar artery during SAC of a basilar tip aneurysm resulting in extensive subarachnoid haemorrhage and brainstem infarction. The second patient died on postoperative day 17 from respiratory arrest following holo left MCA territory infarction as a result of periprocedural parent vessel thrombosis on day one post SAC of a left MCA aneurysm despite dual anti-aggregate medication. The third patient was lost to angiographic and clinical follow-up but on discussion with the patient's relatives was found to have died of unrelated causes.
Parent vessel dissection during the index procedure was experienced in three cases $(3 / 115 ; 2.6 \%)$. Intraprocedural thromboembolic events occurred in five cases $(5 / 115 ; 4.3 \%)$, with three patients experiencing a clinical deficit postoperatively but none resulting in an increase in baseline $\mathrm{mRS}$ at follow-up. Coil prolapse was seen in five cases $(5 / 115 ; 4.3 \%)$, with three arising from the unassisted cohort and two from the stent-assisted cohort.

Five patients $(5 / 115 ; 4.3 \%)$ had an intracranial haemorrhage either intraprocedurally, periprocedurally or within the follow-up time window (table 4). Four subarachnoid haemorrhages were noted, with two events occurring during the index treatment procedure (one intraprocedural aneurysm rupture, one parent vessel dissection with $\mathrm{SAH}$ ), one periprocedural aneurysm rupture (day three postoperatively) and one delayed rupture of a treated index aneurysm 5 months postoperatively. There was one intraparenchymal haemorrhage $(5.5 \mathrm{~cm}$ right frontoparietal intracranial haemorrhage), which occurred on day 19 post SAC of a basilar tip aneurysm. All intracranial haemorrhages occurred in the SAC population.

\section{DISCUSSION}

Our retrospective, core lab adjudicated study of 115 patients from 10 treating centres with unruptured wide-neck aneurysms arising from the MCA bifurcation or basilar apex using FDA-approved devices demonstrates modest complete occlusion rates and durability at follow-up. This reflects the challenging nature of this subset of aneurysm and a current but

Table 4 Adverse events by total pool, treatment modality and aneurysm location

\begin{tabular}{|c|c|c|c|c|c|c|}
\hline \multirow[b]{2}{*}{ Adverse events } & \multirow{2}{*}{$\begin{array}{l}\text { Pool } \\
N=115\end{array}$} & \multicolumn{3}{|c|}{ By treatment type } & \multicolumn{2}{|l|}{ By location } \\
\hline & & $\begin{array}{l}\text { Unassisted } \\
(\mathrm{N}=37)\end{array}$ & $\begin{array}{l}\text { Stent } \\
(\mathrm{N}=70)\end{array}$ & $\begin{array}{l}\text { Balloon } \\
(\mathrm{N}=8)\end{array}$ & $\begin{array}{l}\text { MCA bifurcation } \\
(\mathrm{N}=46)\end{array}$ & $\begin{array}{l}\text { Basilar apex } \\
(\mathrm{N}=69)\end{array}$ \\
\hline \multicolumn{7}{|l|}{ Adverse events, self-reported } \\
\hline Intracranial haemorrhage & $5 / 11(4.3)$ & $0 / 37(0)$ & $5 / 70(7.1)$ & $0 / 8(0)$ & $2 / 46(4.3)$ & $3 / 6(4.3)$ \\
\hline Acute ischaemic stroke & $3 / 11(2.6)$ & 2/37 (5.4) & $1 / 70(1.4)$ & $0 / 8(0)$ & $2 / 46(4.3)$ & $1 / 6(1.4)$ \\
\hline Vessel dissection & 3/11 (2.6) & 2/37 (5.4) & $1 / 70(1.4)$ & $0 / 8(0)$ & $0 / 46(0)$ & $3 / 6(4.3)$ \\
\hline \multicolumn{7}{|l|}{ Intraprocedural adverse events } \\
\hline Thromboembolic event & $5 / 11(4.3)$ & 2/37 (5.4) & $2 / 70(2.9)$ & $1 / 8(12.5)$ & $3 / 46(6.5)$ & $2 / 69(2.9)$ \\
\hline Medication given & $5 / 11(4.3)$ & 2/37 (5.4) & $2 / 70(2.9)$ & $1 / 8(12.5)$ & $3 / 46(6.5)$ & $2 / 69(2.9)$ \\
\hline Intraprocedural aneurysm rupture & $1 / 11(0.9)$ & $0 / 37(0)$ & $1 / 70(1.4)$ & $0 / 8(0)$ & $1 / 46(2.2)$ & $0 / 69(0)$ \\
\hline EVD placed & $1 / 11(0.9)$ & $0 / 37(0)$ & $1 / 70(1.4)$ & $0 / 8(0)$ & $0 / 46(0)$ & $1 / 6(1.4)$ \\
\hline Parent artery/vessel dissection & $3 / 11(2.6)$ & 2/37 (5.4) & $1 / 70(1.4)$ & $0 / 8(0)$ & $0 / 46(0)$ & $3 / 6(4.3)$ \\
\hline Coil prolapse & $5 / 11(4.3)$ & $3 / 37(8.1)$ & $2 / 70(2.9)$ & $0 / 8(0)$ & $2 / 46(4.3)$ & $3 / 6(4.3)$ \\
\hline Vasospasm & 1/11 (0.9) & $0 / 37(0)$ & 1/70 (1.4) & $0 / 8(0)$ & $1 / 46(2.2)$ & 0/69 (0) \\
\hline
\end{tabular}


potentially changing shortcoming of the FDA-approved devices available to manage them. In our series, serious adverse events occurred in eight cases (6.9\%), including two procedure-related mortalities $(1.7 \%)$. The majority of aneurysms treated arose from the basilar apex (60\%), a location associated with significant morbidity and mortality when managed using traditional microsurgical techniques. ${ }^{11-13}$

The 2015 follow-up to the ISAT trial demonstrated that re-bleeding was more likely following endovascular coiling than after neurosurgical clipping, although there was a small increase in absolute risk. ${ }^{14}$ The same study, however, confirmed the probability of disease-free survival was significantly greater in the endovascular group than in the neurosurgical group at 10 years.

Previous studies investigating SAC have shown efficacy with excellent long-term results and satisfactory safety. ${ }^{15-18}$ However, most studies have included sidewall wide-neck aneurysms, which are known to achieve higher rates of satisfactory occlusion and none have been specifically designed using a core lab for angiographic outcomes. ${ }^{19}{ }^{20}$ Despite these encouraging but self-reported results, endovascular surgery for certain aneurysm locations and morphologies has been limited by both anatomical location and technical/device-related factors. Early publications examining these lesions predated the availability of adjunctive technologies such as balloon remodelling microcatheters and dedicated neurovascular stents. These early studies demonstrated procedural safety for the endovascular treatment of wide-neck branching lesions but poor packing densities and resultant low occlusion rates of between $15 \%$ and $19 \% .{ }^{21-23}$

A composite evaluation of the described modern literature to date shows a modest self-reported complete occlusion rate (RR1) of $42 \%$ (complete occlusions divided by total patients). ${ }^{462425}$ Additionally, in a recent meta-analysis, Fiorella et al evaluated angiographic outcomes for wide-neck bifurcation aneurysms treated with either surgical clipping or endovascular techniques. The authors acknowledged many of the papers did not use core lab evaluation. They applied a core lab adjustment technique and derived adjusted RR1 and composite secured (RR1 and RR2) occlusion rates of 39.8\% and $43.8 \%$ respectively for endovascular therapy. ${ }^{18}$ When level one studies were isolated, the complete occlusion rate was substantially lower (28.7\%). Our core lab adjudicated study specifically evaluating MCA and basilar apex bifurcation aneurysms demonstrates complete aneurysm occlusion rates (RR1) of $30.6 \%$ at follow-up (mean $48.7 \pm 35.6$ weeks) and composite secured (RR1 and RR 2) rate of 63\%, which varies somewhat from Fiorella's results.

Prior to our study, the vast majority of available data on the endovascular treatment of wide-neck bifurcation aneurysms was derived from retrospective, self-adjudicated series. ${ }^{4} 62425$ Rezek et al demonstrated that retrospective, non-independently adjudicated studies will consistently overestimate treatment benefit and underestimate complication rates. ${ }^{2627}$ Our study confirms their findings, with a statistically significant direction towards self-reporting Raymond Roy class one occlusion rates over the core lab both immediately following treatment and at follow-up (OR 1.84, 95\% CI 1.15 to 2.95 ; and OR $1.75,95 \% \mathrm{CI} 1.08$ to 2.83 respectively). This has significant implications for the evaluation of any new device undergoing regulatory approval when addressing efficacy and safety benchmarks.

\section{Limitations}

Our study has several limitations. First, while the questions and planned analysis were designed in a prospective fashion, this investigation remains a retrospective study reviewing previously performed procedures, and as such has all the bias inherent in such a design. Second, although the angiographic and clinical follow-up was available in 115 and 105 patients respectively, the reporting of events and clinical outcomes are dependent on the individual centres, which may be subject to bias and the follow-up period for the entire cohort has a broad SD. In addition, the relatively small number of balloon assisted treatment cases makes evaluation of outcomes and safety difficult to interpret with respect to this subset.

The results reflect real world practice at 10 established neuroendovascular centres in the United States and can probably be extrapolated to most centres that perform endovascular aneurysm treatment. The patient characteristics, aneurysm morphology and devices used are likely to be consistent across most centres in the United States at the time of writing.

\section{CONCLUSION}

This multicentre, retrospective core lab adjudicated series of 115 patients with wide-neck aneurysms arising at the MCA bifurcation or basilar apex treated by endovascular techniques using FDA-approved devices demonstrates a core lab adjudicated Raymond Roy class one occlusion rate of $30.6 \%$ at a mean follow-up of 48.8 weeks (SD \pm 35.6 ). Procedural morbidity and mortality were within published limits for this subgroup of challenging aneurysms, with $93.2 \%$ of patients being mRS $0-2$ at follow-up. Self-reported results favour better angiographic outcomes. Statistically significant ORs favouring self-reporting of RR class one outcomes versus the core lab was demonstrated both immediately following treatment and at follow-up for the pool. Our study supports the ongoing need for the development and evaluation of novel endovascular devices specifically designed to treat complex intracranial aneurysms. In addition, it is imperative that any analysis of efficacy uses core lab adjudicated outcomes and that any performance criteria used are based on core lab adjudicated data.

\section{Author affiliations \\ ${ }^{1}$ Department of Neurosurgery, Mount Sinai Hospital, New York City, New York, USA ${ }^{2}$ Department of Neurological Surgery, Wake Forest University, Winston-Salem, North Carolina, USA \\ ${ }^{3}$ Department of Neurosurgery, Massachusetts General Hospital, Boston, Massachusetts, USA \\ ${ }^{4}$ Department of Neurosurgery, University of Michigan, Ann Arbor, Michigan, USA ${ }^{5}$ Department of Neurosurgery, University of Louisville, Louisville, Kentucky, USA ${ }^{6}$ Department of Neurosurgery, Albany Medical Center, Albany, New York, USA ${ }^{7}$ Department of Neurosurgery, Lyerly Baptist, Jacksonville, Florida, USA \\ ${ }^{8}$ Department of Neurosurgery, UT Southwestern Medical Center, Dallas, Texas, USA ${ }^{9}$ Department of Diagnostic Radiology and Nuclear Medicine, University of Maryland, Baltimore, Maryland, USA \\ ${ }^{10}$ Neurointerventional Surgery, Northwestern Medicine at Central DuPage Hospital, Winfield, Illinois, USA \\ ${ }^{11}$ Department of Neurosurgery, University at Buffalo, Buffalo, New York, USA}

Acknowledgements Philanthropic funding from Daniel and Nancy Paduano supported the wages of a statistician for the study.

Contributors All authors made substantial contributions to (1) the conception or design of the work, or the acquisition, analysis, or interpretation of data for the work; (2) drafting of the work or revising it critically for important intellectual content; (3) final approval of the version to be published; and are in agreement to be accountable for all aspects of the work in ensuring that questions related to the accuracy or integrity of any part of the work are appropriately investigated and resolved. 
Funding This work was supported by MEDTRonic Neurovascular, grant number GCO\#16-0576. Further philanthropic funding was also provided by Daniel and Nancy Paduano that helped support wages for a statistician for the study.

Competing interests AHS, ABP, RFJ are consultants for Medtronic Neurovascular RFJ has received research funding from Medtronic Neuorvascular. BGW is a proctor for Medtronic Neurovascular.

Patient consent Not required.

Ethics approval Multiple institutional review boards.

Provenance and peer review Not commissioned; externally peer reviewed.

Data sharing statement Data could be made available by contacting the corresponding author following IRB approval.

(C) Article author(s) (or their employer(s) unless otherwise stated in the text of the article) 2019. All rights reserved. No commercial use is permitted unless otherwise expressly granted.

\section{REFERENCES}

1 Molyneux A, Kerr R, Stratton I, et al. International Subarachnoid Aneurysm Trial (ISAT) of neurosurgical clipping versus endovascular coiling in 2143 patients with ruptured intracranial aneurysms: a randomised trial. Lancet 2002;360:1267-74.

2 Castaño C, Terceño M, Remollo S, et al. Endovascular treatment of wide-neck intracranial bifurcation aneurysms with ' $Y$ '-configuration, double Neuroform $\mathbb{R}$ stents-assisted coiling technique: Experience in a single center. Interv Neuroradiol 2017;23:362-70.

3 Alfke K, Straube T, Dörner L, et al. Treatment of intracranial broad-neck aneurysms with a new self-expanding stent and coil embolization. AJNR Am J Neuroradiol 2004;25:584-91.

4 Fargen KM, Mocco J, Neal D, et al. A multicenter study of stent-assisted coiling of cerebral aneurysms with a $Y$ configuration. Neurosurgery 2013;73:466-72.

5 Wanke I, Doerfler A, Schoch B, et al. Treatment of wide-necked intracranial aneurysms with a self-expanding stent system: initial clinical experience. AJNR Am J Neuroradiol 2003:24:1192-9.

6 Spiotta AM, Gupta R, Fiorella D, et al. Mid-term results of endovascular coiling of wide-necked aneurysms using double stents in a Y configuration. Neurosurgery 2011;69:421-9.

7 Pierot L, Biondi A. Endovascular techniques for the management of wide-neck intracranial bifurcation aneurysms: A critical review of the literature. J Neuroradiol 2016:43:167-75.

8 Rezek I, Lingineni RK, Sneade M, et al. Differences in the angiographic evaluation of coiled cerebral aneurysms between a core laboratory reader and operators: results of the cerecyte coil trial. AJNR Am J Neuroradiol 2014;35:124-7.

9 Mascitelli JR, Moyle H, Oermann EK, et al. An update to the raymond-roy occlusion classification of intracranial aneurysms treated with coil embolization. J Neurointerv Surg 2015;7:496-502.

10 van Amerongen MJ, Boogaarts HD, de Vries J, et al. MRA versus DSA for followup of coiled intracranial aneurysms: a meta-analysis. AJNR Am J Neuroradiol 2014:35:1655-61
11 Nanda A, Sonig A, Banerjee AD, et al. Microsurgical management of basilar artery apex aneurysms: a single surgeon's experience from Louisiana State University, Shreveport. World Neurosurg 2014;82(1-2):118-29.

12 Lawton MT. Basilar apex aneurysms: surgical results and perspectives from an initial experience. Neurosurgery 2002;50:1-10.

13 Lusseveld E, Brilstra EH, Nijssen PCG, et al. Endovascular coiling versus neurosurgical clipping in patients with a ruptured basilar tip aneurysm. J Neurol Neurosurg Psychiatr. BMJ Publishing Group 2002;73:591-3.

14 Molyneux AJ, Birks J, Clarke A, et al. The durability of endovascular coiling versus neurosurgical clipping of ruptured cerebral aneurysms: 18 year follow-up of the UK cohort of the International Subarachnoid Aneurysm Trial (ISAT). Lancet 2015;385:691-7.

15 Aydin K, Arat A, Sencer S, et al. Stent-assisted coiling of wide-neck intracranial aneurysms using low-profile LEO baby stents: initial and midterm results. AJNR Am J Neuroradiol 2015;36:1934-41.

16 Chalouhi N, Jabbour P, Singhal S, et al. Stent-assisted coiling of intracranial aneurysms: predictors of complications, recanalization, and outcome in 508 cases. Stroke 2013;44:1348-53.

17 Poncyljusz W, Biliński P, Safranow K, et al. The LVIS/LVIS Jr. stents in the treatment of wide-neck intracranial aneurysms: multicentre registry. J Neurointerv Surg 2015;7:524-9.

18 Fiorella D, Arthur AS, Chiacchierini R, et al. How safe and effective are existing treatments for wide-necked bifurcation aneurysms? Literature-based objective performance criteria for safety and effectiveness. J Neurointerv Surg 2017;9:1197-201.

19 Fiorella D, Albuquerque FC, Woo H, et al. Neuroform stent assisted aneurysm treatment: evolving treatment strategies, complications and results of long term follow-up. J Neurointerv Surg 2010;2:16-22.

20 Fargen $\mathrm{KM}$, Hoh BL, Welch BG, et al. Long-term results of enterprise stent-assisted coiling of cerebral aneurysms. Neurosurgery 2012;71:239-44. -discussion244.

21 Bavinzski G, Killer M, Gruber A, et al. Treatment of basilar artery bifurcation aneurysms by using Guglielmi detachable coils: a 6-year experience. J Neurosurg 1999;90:843-52

22 McDougall CG, Halbach VV, Dowd CF, et al. Endovascular treatment of basilar tip aneurysms using electrolytically detachable coils. J Neurosurg 1996;84:393-9.

23 Raymond J, Roy D, Bojanowski M, et al. Endovascular treatment of acutely ruptured and unruptured aneurysms of the basilar bifurcation. J Neurosurg 1997:86:211-9.

24 Lodi Y, Latorre J, El-Zammar Z, et al. Single stage versus multi-staged stent-assisted endovascular repair of intracranial aneurysms. J Vasc Interv Neurol 2011;4:24-8.

25 Zhang JZ, Yang PF, Huang QH, et al. Stent-assisted coiling strategies for the treatment of wide-necked basilar artery bifurcation aneurysms. J Clin Neurosci 2014;21:962-7.

26 Rezek I, Mousan G, Wang Z, et al. Effect of core laboratory and multiple-reader interpretation of angiographic images on follow-up outcomes of coiled cerebral aneurysms: a systematic review and meta-analysis. AJNR Am J Neuroradiol 2013;34:1380-4

27 Rezek I, Lingineni RK, Sneade M, et al. Differences in the angiographic evaluation of coiled cerebral aneurysms between a core laboratory reader and operators: results of the Cerecyte Coil Trial. AJNR Am J Neuroradiol 2014;35:124-7. 